\title{
SOC2010: revision of the Standard Occupational Classification
}

\section{SUMMARY}

This article describes the revision of the Standard Occupational Classification from its 2000 to its 2010 version (SOC2010).

It details the revision process, outlines the major areas of change and illustrates the impact of these changes on national estimates of employment by occupation. Given that the revision of a classification introduces potential discontinuities in the interpretation of occupational information over time, the final section discusses ways in which such discontinuities can be minimised.

\section{Key points}

- In June 2010 the Office for National Statistics (ONS) published as two volumes a new edition of the Standard Occupational Classification (SOC2010). This is the second revision of the classification first introduced in 1990 (SOC90) and revised in 2000 (SOC2000).

- The revised classification was developed by ONS in collaboration with experts in occupational classification from the Institute for Employment Research (IER) at the University of Warwick. It results from consultations with, and advice from, a wide variety of users and producers of occupational statistics, including employer associations, professional bodies, trades unions, training organisations, academics and national and local government departments and agencies.

- The revised classification addresses a major problem evident within UK occupational statistics - the high proportion of occupations classified to Major Group 1 'Managers and senior officials' compared with most other European countries and the USA. Close examination of the main tasks and duties performed in a range of occupations classified to this major group in SOC2000 and redefinition of key managerial functions within the Standard Occupational Classification, led to the reallocation of numerous job titles from SOC2010 Major Group
1 to other major groups, reducing the size of this major group from 19 per cent to 12.8 per cent of male employment and from 10.8 per cent to 6.3 per cent for female employment (Labour Force Survey (LFS), Q1 2007).

- The classification is updated and improved in a number of areas, including information and communication technology occupations; health-related occupations; leisure and travel related jobs; culture, the arts and sports occupations and the care sector.

- Nursing occupations have been reclassified from Major Group 3 (Associate professional and technical occupations) to Major Group 2 (Professional occupations). This reflects the growing proportion of nurses with a degree level education following the raising of entry requirements.

- To improve alignment with the recently revised International Standard Classification of Occupations (ISCO08), a number of supervisory unit groups have been added to the classification.

- The new classification will be used to code occupational details provided in the forthcoming Census of Population. By 2012 most other sources of occupational information (for example, registration statistics, national surveys and job vacancy details) will make use of SOC2010. 


\section{Introduction}

classification of occupations provides a framework for describing the kind of work that people do. By organising jobs into groups that reflect the typical skills and expertise required to perform them well, occupational classifications enable analysts to measure skill-based changes in the labour market, match jobs to the skills of workers and/or provide relevant advice to job seekers. To achieve these objectives, a classification must be both up-to-date and have a clear, meaningful structure appropriate for the uses to which it will be put.

Jobs are not static entities. Innovation and the introduction of new technologies, changes in the organisation of work, revisions to occupational training and qualification requirements, together with shifts in demand for different types of goods and services and the ways in which these are met - all impact on the nature of occupations. To measure and monitor such changes, analysts need to record occupational information within a stable framework. However, as change progresses, there is also a need to adjust the classification from time to time, ensuring that the classification reflects new areas of work and associated training and qualification requirements.

The Office for National Statistics (ONS) has adopted a ten year cycle for the revision of the UK national occupational classification. While the conceptual basis of the UK national occupational classification has remained unchanged since $1990^{1}$, the 2010 Standard Occupational Classification is now the second revision. Previous articles have described the introduction of the Standard Occupational Classification in 1990 (Thomas and Elias, 1989) and its revision in 2000 (Elias et al, 2000). This article presents a summary of the main changes that have been made to the 2000 version of the Standard Occupational Classification $^{2}$ (referred to as SOC2000), redefining the national standard as the 2010 version of the Standard Occupational Classification (referred to as SOC2010).

The main areas of change involve:

- the introduction of a stricter definition of managers

- the reallocation of most nursing occupations from Major Group 3 to Major Group 2

- a reclassification of occupations associated with information technologies; and

- further alignment with the 2008 revision of the International Standard
Classification of Occupations (ISCO08), specifically via the introduction of a limited number of supervisory unit groups

Details of these changes are given in the following sections, with the final section specifically addressing issues of maintaining continuity alongside the need for change.

\section{The redefinition of managers}

Relative to many other countries, a significantly higher proportion of the working population in the UK is classified via SOC2000 as managers ${ }^{3}$. An international comparison of occupational structures based on information collected from 25 European countries and the USA in 2003 (European Commission, 2004) indicated that the proportions of employment in ISCO88 Major Group 1 in nearly all EU countries and the US show a deviation from the EU average of $+/-2.5$ percentage points ${ }^{4}$. However, the UK and Ireland ${ }^{5}$ stand out by showing a deviation of +6 percentage points from the EU average. It is unlikely that this reflects major differences in the organisation and structure of work in the UK and most probably relates to the use of the job title 'manager' and associated classification methods and procedures in SOC2000.

Closer examination of EU Labour Force Survey statistics shows that the problem is located within ISCO Sub major Group 12 'Corporate Managers', a category which corresponds reasonably well with SOC2000 Sub major Group 11 'Corporate Managers'. This problem was noted during the process of revising SOC 90 to create SOC2000.

A number of SOC90 job titles which were indexed to SOC90 Sub major Group 11 were repositioned, particularly job titles using the word 'executive' or 'administrator' which were reallocated to Major Groups 3 or 4 of SOC2000. However, another change was also implemented during the development of SOC2000 which countered the effect of repositioning these job titles. With a few exceptions, all job titles with the word 'manager' in the title were allocated to Major Group 1. This rule was adopted to simplify the allocation of job titles within the (then) developing National Statistics Socio-economic Classification. The net effect of these changes was to reduce the size of Major Group 1 as defined via the previous classification (SOC90) from 19 per cent of male employment in 1996/97 to 18 per cent when defined in SOC2000, and from 12 per cent to 8 per cent for females (ONS, 2000a).

In developing SOC2010 this issue has been readdressed. The fact that UK statistical practice in this area is still at odds with the major countries elsewhere in the EU and the US suggests that to take no action is not an option, in that it would ultimately diminish the perceived value within the global community of official occupational information from the UK. Analysts and policy makers frequently make use of occupational information at this broad aggregate level. A lack of national comparability at this highly visible level could give rise to misleading interpretation of national statistical evidence.

\section{Defining managers}

In discussion with occupational experts from other countries ${ }^{6}$ it was apparent that a more stringent approach is taken with the use of the job title 'manager' (or its equivalent in other languages). The title 'manager', qualified in some way, is frequently used in the UK to denote what would be regarded as supervisory or administrative positions in many other countries. Furthermore, the title is often used in the UK to denote the management of a set of activities that constitute a narrowly-defined role, rather than the broader and more strategic managerial functions that characterise managerial functions in other countries.

The SOC review team approached this issue first by examining more closely the definition of corporate managers as described in SOC2000 and in the International Standard Classification of Occupations (ISCO08) ${ }^{7}$.

The international definition of managers stresses the role of the manager as one for which the key tasks are 'planning, organising, directing, controlling and coordinating resources (financial, administrative, human and technical). The UK definition uses phrases such as 'organise and coordinate', which has led to a broad and flexible interpretation of the managerial role.

To effect a definition of the managerial role which accords more closely with the broader, more strategic definition as used in ISCO 88, the definition of managers within SOC2000 Major Group 1 was changed from its current definition:

'This major group covers occupations whose main tasks consist of the direction and coordination of the functioning of organisations and businesses, including internal departments and sections, often with the help of subordinate managers and supervisors.' 
to the following definition:

'This major group covers occupations whose tasks consist of planning, directing and coordinating resources to achieve the efficient functioning of organisations and businesses.

This revised definition focuses upon the role of manager as one which is associated specifically with control over resources (planning, directing and coordinating) at the enterprise or organisational level and makes more explicit the strategic elements of the job rather than the day-to-day tasks. Where the job title 'manager' is used yet the job description does not indicate significant responsibilities for strategic control over resources (financial, material or human), consideration was given to the reallocation of such job titles and their associated task descriptions to alternative major groups. This required a careful examination of the mechanisms (index rules, guidance notes, coding procedures, and so on) by which such job titles and descriptions could be identified and excluded from Major Group 1.

\section{Evidence to support the} reclassification of managers Two major sources of information were used to assist with the redefinition of managers in SOC2010: text responses to questions about the kind of work people do from the Labour Force Surveys (2002-07) and a sub sample of information from the 2001 Census of Population. Suitably anonymised individual records from these sources provided just over 280,000 and 223,000 job titles respectively. Despite slight differences in the questions and the later timing of the Labour Force Surveys, both sources show fairly similar proportions of job titles classified to Major Group 1 (18.6 per cent and 10.7 per cent for males and females respectively in the Labour Force Surveys compared with 18 per cent and 10.5 per cent in the Census of Population).

All jobs classified within each unit group of Major Group 1 of SOC 2000 were analysed in detail, noting the text descriptions of the main tasks. This revealed that there is a number of commonly occurring job titles where the tasks were associated primarily with the organisation of a limited set of related duties, but did not constitute 'planning, directing and coordinating resources to achieve the efficient functioning of organisations and businesses.' Foremost among such job titles is the term 'project manager'. Inspection of the text responses to the question 'What did you mainly do in your job?' revealed that many people who gave their job title as 'project manager' were engaged in technical work or construction activities. Typical responses would be 'Implement software changes in companies', 'coordinating building projects', 'manage internet connections', 'updating health and safety contract for clients' 'supervise a team helping people with mental health problems get houses' and 'mainly giving IT support'.

The coding index to SOC2000 instructs coders to classify the text 'project manager' to a range of unit groups in Major Group 1, from 1121 Production, works and maintenance managers to 1185 Residential and day care managers. Analysis of job titles in the composite Labour Force Survey file indicated that there were 1,753 cases $(0.6$ per cent of all jobs) where the words 'project manager' or 'projects manager' appeared in the job title. Of these, 93 per cent had been coded to Sub major Group 11 Corporate Managers, predominantly to unit groups 1136 Information and communication technology managers, 1121 Production, works and maintenance managers and 1122 Managers in construction.

Job titles containing the words 'project(s) manager' accounted for more than 5 per cent of all the job titles classified to sub major group 11 in the composite Labour Force Survey file. We note also that 11 per cent of job titles containing the words 'project(s) manager' were not coded to SOC2000 by Labour Force Survey coders, indicating the difficulty of coding this ambiguous job title in the absence of any additional information. Job titles containing the words 'project(s) manager' and coded in SOC2000 to Major Group 1 were repositioned in SOC2010 to unit groups within Major Group 2, as shown in Table 1. Note that most of the SOC2010 unit groups listed in this table are newly created, some to facilitate this repositioning of 'project managers' (for example 2424 Business and financial project management professionals; 2436 Construction project managers and related professionals).

In addition to the repositioning of 'project managers' in SOC2010, a number of other job titles were investigated in detail to determine whether or not they should be reclassified. Where the job title appears with no additional qualifying information, it is coded within SOC2000 as shown in parentheses. These are listed as follows, together with the associated SOC2000 unit group $(s)$ to which they were allocated:

- Administration manager (1152)

- Accounts manager (1152)

- Account manager $(1132,1134,1135$, 1151)

- Sales manager (1132)

- Office manager (1152)

- Payroll manager (1152)

- Practice manager (1152)

- Business manager (various - depends on sector of activity)

- Business development manager (various - depends on sector of activity)

Table 2 provides information from the Labour Force Survey showing, for each of these job titles, the percentage of job holders with a degree, the percentage with supervisory responsibilities, the percentage stating in their task descriptions that they had some degree of control across the establishment at which they worked and the extent of their control over resources. Based upon the information shown in this table, further case-by-case investigations were carried out for all jobs classified within the unit groups where these job titles are currently positioned. Index entries were

\section{Table 1}

\section{Re-coding of 'project manager' titles}

\begin{tabular}{lll}
\hline SOC2000 & SOC2010 & Index entry \\
\hline 1121 & 2424 & Manager, projects \\
1121 & 2129 & Manager, project (manufacturing) \\
1122 & 2436 & Manager, projects (building and contracting) \\
1113 & 2424 & Manager, project (local government) \\
1134 & 2473 & Manager, projects (advertising) \\
1136 & 2135 & Manager, project, development, software \\
1136 & 2134 & Manager, project, IT \\
1136 & 2134 & Manager, project (computing) \\
1136 & 2134 & Manager, project (telecommunications) \\
1137 & 2119 & Manager, project (research and development) \\
1151 & 2424 & Manager, project (financial services) \\
1184 & 2424 & Manager, project (social services) \\
1185 & 2424 & Manager, project (social services: residential) \\
1239 & 2424 & Manager, project (publishing) \\
\hline
\end{tabular}


Table 2

Specific managerial job titles: qualifications, supervision, degree of control over establishment and resources

\begin{tabular}{|c|c|c|c|c|c|c|c|c|}
\hline \multirow[b]{2}{*}{ Specific job title } & \multirow[b]{2}{*}{ Number of cases } & \multirow{2}{*}{$\begin{array}{r}\text { Has a degree? } \\
\text { (per cent) }\end{array}$} & \multirow{2}{*}{$\begin{array}{r}\text { Responsible for } \\
\text { supervising } \\
\text { other people? } \\
\text { (per cent) }\end{array}$} & \multirow{2}{*}{$\begin{array}{r}\text { Has some } \\
\text { control over } \\
\text { establishment?- } \\
\text { (per cent) }\end{array}$} & \multicolumn{3}{|c|}{ Control over resources? (per cent) } & \multirow[b]{2}{*}{ Not stated } \\
\hline & & & & & High & Medium & Low & \\
\hline Administration manager & 258 & 7.4 & 80.1 & 6.6 & 25.2 & 32.2 & 38.4 & 4.3 \\
\hline Accounts manager & 361 & 16.3 & 62.8 & 0.3 & 3.9 & 25.5 & 67.0 & 3.6 \\
\hline Account manager & 412 & 26.9 & 44.8 & 1.7 & 2.4 & 16.7 & 77.4 & 3.4 \\
\hline Sales manager & 1,012 & 13.9 & 74.2 & 5.0 & 8.5 & 34.5 & 54.2 & 2.8 \\
\hline Office manager & 903 & 11.0 & 77.8 & 5.5 & 37.9 & 21.9 & 36.0 & 4.2 \\
\hline Payroll manager & 73 & 9.6 & 82.2 & 1.4 & 4.1 & 43.8 & 52.1 & * \\
\hline Practice manager & 218 & 16.1 & 90.4 & 42.7 & 61.0 & 16.5 & 16.5 & 6.0 \\
\hline Business manager & 223 & 35.0 & 82.0 & 16.6 & 18.4 & 26.9 & 42.6 & 12.1 \\
\hline Business development manager & 269 & 34.6 & 55.0 & 4.5 & 3.3 & 11.9 & 75.1 & 9.7 \\
\hline Total & 3,729 & 17.2 & 71.3 & 7.2 & 18.9 & 25.5 & 51.1 & 4.6 \\
\hline
\end{tabular}

Note:

Source: Labour Force Survey composite file 2003-07

* indicates that the number in the cell fell below threshold for reporting.

Table 3

The redefinition of certain SOC2000 managerial occupation in SOC2010

\begin{tabular}{|c|c|c|c|c|}
\hline \multicolumn{2}{|c|}{ SOC2000 } & \multicolumn{3}{|c|}{ Repositioned in SOC2010 to: } \\
\hline \multirow[t]{3}{*}{1121} & Production works and maintenance managers & 1121 & Production managers and directors in manufacturing & $81 \%$ \\
\hline & $(\mathrm{N}=782)$ & 2129 & Engineering professionals n.e.c. & $7 \%$ \\
\hline & & 5 & SKILLED TRADES OCCUPATIONS & $6 \%$ \\
\hline \multirow[t]{3}{*}{1122} & Managers in construction & 1122 & Production managers and directors in construction & $72 \%$ \\
\hline & $(\mathrm{N}=659)$ & 2436 & Construction project managers and related professionals & $23 \%$ \\
\hline & & 5319 & Construction and building trades n.e.c. & $3 \%$ \\
\hline \multirow[t]{4}{*}{1131} & Financial managers and chartered secretaries & 1131 & Financial managers and directors & $74 \%$ \\
\hline & $(\mathrm{N}=438)$ & 2424 & Business and financial project management professionals & $5 \%$ \\
\hline & & 2429 & Business, research and administrative professionals n.e.c. & $5 \%$ \\
\hline & & 3538 & Financial accounts managers & $12 \%$ \\
\hline \multirow[t]{3}{*}{1132} & Marketing and sales managers & 1132 & Marketing and sales directors & $33 \%$ \\
\hline & $(\mathrm{N}=1,101)$ & 2424 & Business and financial project management professionals & $4 \%$ \\
\hline & & 3545 & Sales accounts and business development managers & $59 \%$ \\
\hline \multirow[t]{3}{*}{1136} & Information and communication technology managers & 1136 & Information technology and telecommunications directors & $31 \%$ \\
\hline & $(\mathrm{N}=607)$ & 2133 & IT specialist managers & $43 \%$ \\
\hline & & 2134 & IT project and programme managers & $22 \%$ \\
\hline \multirow[t]{5}{*}{1151} & Financial institution managers & 1150 & Financial institution managers and directors & $47 \%$ \\
\hline & $(\mathrm{N}=413)$ & 2424 & Business and financial project management professionals & $12 \%$ \\
\hline & & 3533 & Insurance underwriters & $3 \%$ \\
\hline & & 3538 & Financial accounts managers & $20 \%$ \\
\hline & & 4123 & Bank and post office clerks & $13 \%$ \\
\hline \multirow[t]{3}{*}{1152} & Office managers & 3538 & Financial accounts managers & $14 \%$ \\
\hline & $(\mathrm{N}=587)$ & 4161 & Office managers & $65 \%$ \\
\hline & & 7220 & Customer service managers and supervisors & $3 \%$ \\
\hline \multirow[t]{2}{*}{1163} & Retail and wholesale managers & 1190 & Managers and directors in retail and wholesale & $87 \%$ \\
\hline & $(\mathrm{N}=944)$ & 7130 & Sales supervisors & $10 \%$ \\
\hline
\end{tabular}

Source: Labour Force Survey January-March 2007 (recoded data file)

modified as appropriate to move specific job titles to Major Groups 2, 3, 4, 5 and 7.

Measuring the impact of change in the definition of managerial occupations

To gain an indication of the effect of these changes on the composition of Major Group 1 , one complete quarter of the Labour Force Survey (January to March 2007) was recoded, reallocating job titles to other unit groups as appropriate. Table 3 shows, for the eight unit groups in SOC2000 most significantly affected by these changes, the unit groups to which job titles are now repositioned in SOC2010.

\section{The reallocation of nursing occupations}

Nursing occupations have previously been classified as 'Associate Professional' occupations. Investigations concluded during the development of SOC2000 showed that only a small proportion of nurses held a high level qualification (university degree or equivalent). This situation has changed significantly over the last ten years. While it is still possible to enter nursing without a degree-level qualification, increasingly it is the case that entry into a nursing occupation is via a degree-level route. Between 1993/94 and 2006/07, the Labour Force Survey 
Table 4

The redefinition of IT and telecommunications occupations in SOC2010

\begin{tabular}{|c|c|c|c|c|c|}
\hline \multicolumn{3}{|c|}{ SOC 2000} & \multicolumn{3}{|c|}{ SOC 2010} \\
\hline \multicolumn{6}{|c|}{ Major Group 1} \\
\hline & 1136 & Information and Communication Technology Managers & & 1136 & Information technology and telecommunications Directors \\
\hline \multicolumn{6}{|c|}{ Major Group 2} \\
\hline \multirow[t]{7}{*}{213} & \multicolumn{2}{|c|}{ Information and communication technology professionals } & 213 & \multicolumn{2}{|c|}{ Information Technology and Telecommunications Professionals } \\
\hline & 2131 & IT Strategy and Planning Professionals & & 2133 & IT specialist managers \\
\hline & 2132 & Software Professional & & 2134 & IT project and programme managers \\
\hline & & & & 2135 & IT Business analysts, architects and systems designers \\
\hline & & & & 2136 & Programmers and software development professionals \\
\hline & & & & 2137 & Web design and development professionals \\
\hline & & & & 2139 & Information technology and telecommunication professionals n.e.c. \\
\hline \multicolumn{6}{|c|}{ Major Group 3} \\
\hline \multirow[t]{3}{*}{313} & \multicolumn{2}{|c|}{ IT Service Delivery Occupations } & 313 & \multicolumn{2}{|c|}{ Information Technology Technicians } \\
\hline & 3131 & IT Operations Technicians & & 3131 & IT operations technicians \\
\hline & 3132 & IT User Support Technicians & & 3132 & IT user support technicians \\
\hline
\end{tabular}

Source: SOC2000 and SOC2010

Table 5

Correspondence between ISCO08 supervisory unit groups and SOC2010 supervisory unit groups

\begin{tabular}{|c|c|c|c|}
\hline \multicolumn{2}{|c|}{ ISCO08 unit groups } & \multicolumn{2}{|l|}{ SOC 2010 unit groups } \\
\hline 3121 & Mining supervisors & Not defined & \\
\hline \multirow[t]{2}{*}{3341} & Office supervisors & Office managers & 4161 \\
\hline & & Administrative and office supervisors & 4162 \\
\hline 3122 & Manufacturing supervisors & Skilled metal and electrical trades supervisors & 5250 \\
\hline 3123 & Construction supervisors & Construction and building trades supervisors & 5330 \\
\hline 5151 & Cleaning and housekeeping supervisors in offices, hotels and other establishments & Cleaning and Housekeeping managers and supervisors & 6240 \\
\hline \multirow[t]{2}{*}{5222} & Shop supervisors & Sales supervisors & 7130 \\
\hline & & Customer service managers and supervisors & 7220 \\
\hline
\end{tabular}

Source: ISCO08 and SOC2010

indicates that the proportion of young nurses (26-35 years old) with a degree-level qualification rose from 4 per cent to 32 per cent. In liaison with the professional body for nursing (Royal College of Nursing) the decision was made to reallocate nursing occupations from Major Group 3 in SOC2000 to Major Group 2 in SOC2010.

\section{The reclassification of occupations associated with information technologies}

Occupations associated with information technology (IT) and telecommunications have been subject to rapid change over the past ten years, with significant growth in web-based communications, a sharp increase in web transactions (for example, advertising, buying, selling) and the application of IT through virtually all sectors of the economy. However, there remains a problem of heterogeneity in the use of job titles in the sector, first noted in the development of SOC2000. In consultation with the lead industry body in this area (e-skills UK), certain changes have been made to the structure of minor group 213 (Information Technology and Telecommunications Professionals). The changes are as shown in Table 4.
The main areas of occupational redefinition are located in Minor Group 213 now termed 'Information Technology and Telecommunications Professionals'. None of the unit groups in this SOC2010 Minor Group shares the same unit group number with SOC2000, indicating that there is no direct correspondence between the unit groups. The Minor Group now holds six unit groups, demonstrating the diversity of job types that is developing in this area.

\section{The introduction of a limited number of supervisory unit groups}

The 2008 revision to the International Standard Classification of Occupations (ISCO08) introduces a limited number of supervisory unit groups. These have been defined in areas of work where the role of the supervisor is distinct and is generally regarded as a separate occupational area from the type of work that is being supervised. Where possible, corresponding supervisory categories have been incorporated within SOC2010. This was not possible for the category 'Mining supervisors' (the resulting unit group would be below the limit of statistical data release for most data sources) and the category
'Manufacturing supervisors' was considered too broadly defined.

Table 5 shows the correspondence between the new ISCO08 categories and their counterparts in SOC2010.

\section{The overall impact of reclassification from $\mathrm{SOC} 2000$ to SOC2010}

To gain some indication of the way in which this revision of the Standard Occupational Classification impacts upon the interpretation of trends in occupational structure of employment in the UK, the 1996/97 winter quarter of the Labour Force Survey was recoded from SOC2000 to SOC2010, comparing this information with similarly recoded data for the 2007 January/ March Quarter of the Labour Force Survey.

Figure $\mathbf{1}$ ( $\mathbf{a}$ and $\mathbf{b}$ ) and Figure $\mathbf{2}$ ( $\mathbf{a}$ and $\mathbf{b}$ ) show the overall impact of these changes at the level of Major Groups of the Standard Occupational Classification. Examining first the effect on male employment, the reclassification of managerial occupations stands out as the single most important change, reducing the size of male employment in Major Group 1 as recorded in the first quarter of 2007 from 19.0 per cent of all employment to 12.8 per cent. 


\section{Figure 1a \\ Percentage distribution of male employment in Dec 1996-Feb 1997, SOC2000 and SOC2010}

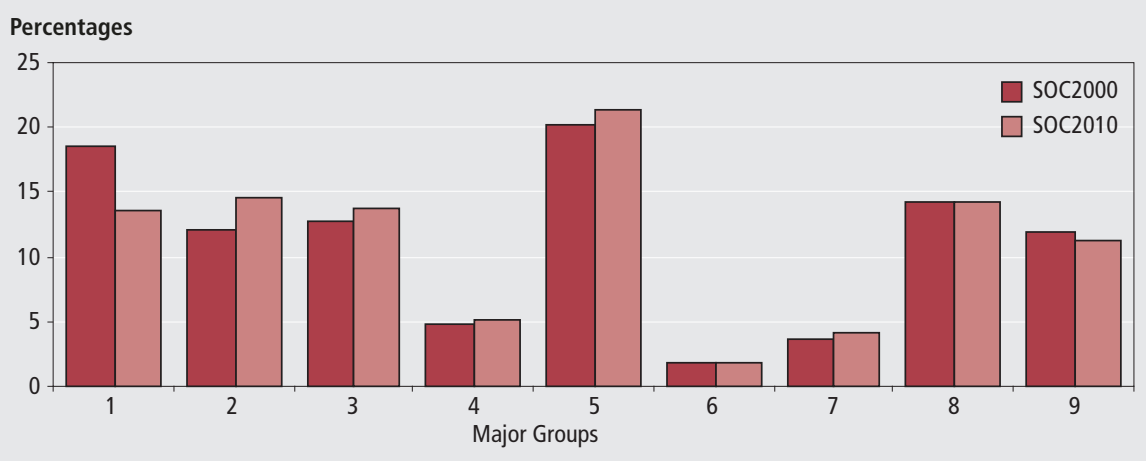

Source: Labour Force Survey (unweighted data)

\section{Figure $1 b$ \\ Percentage distribution of male employment in Jan-Mar 2007, SOC2000 and SOC2010}

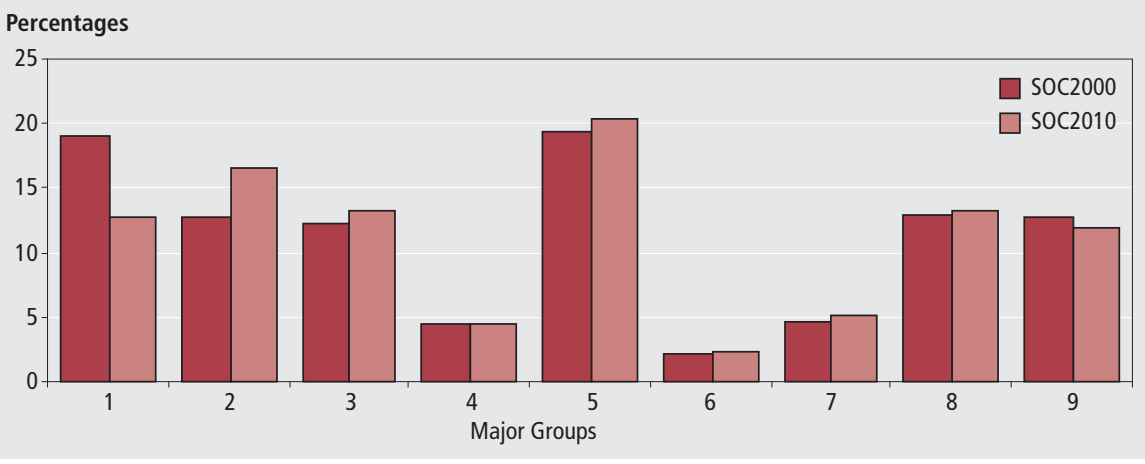

Source: Labour Force Survey (unweighted data)

The reclassification of the winter quarter 1996/97 Labour Force Survey shows a similar effect, with the share of male employment in this Major Group falling from 18.5 to a 13.6 per cent. Corresponding rises take place in Major Groups 2, 3 and 5 in both periods. Comparing the changes recorded between 1996/97 and 2007 by the two classifications shows that the modest growth over this decade in both Major Groups 1 and 2 by SOC2000 now become a decline in the occupational share held by Major Group 1 of SOC2010 and a corresponding increase in the share of employment in SOC2010 Major Group 2. This arises because of the significant growth which took place in this ten year period in those occupations which are now reallocated from Major Group 1 of SOC2000 to Major Group 2 of SOC2010.

Figures $2 \mathrm{a}$ and $2 \mathrm{~b}$ show similar information for female employment. Again, a fall in the share of employment classified to Major Group 1 is recorded, though the decline is not as great as is shown for males. The reclassification of nursing occupations from Major Group 3 to Major Group 2 also has significant impact at this level of aggregation, with the share of female employment in SOC2000 Major Group 3 (as measured in the first quarter of 2007) falling from 14.0 per cent to 10.2 per cent.

At the level of sub major groups, of which there are 25 in SOC2000 and SOC2010, there is a high degree of correspondence between these groups as defined in both classifications for nine out of 25 groups (>95 per cent correspondence) and a reasonable degree of correspondence (85-95 per cent) for 11 out of 25 sub major groups. In five sub major groups the correspondence between the classification drops below 85 per cent. More detailed analysis of the correspondence between the classifications at the sub major group level is shown in Table 6.

\section{Managing change and continuity}

There is a tension between the need for continuity in the application and use of an occupational classification, thereby providing a stable framework for analysis of trends, and the need for revision of the classification, ensuring the classification is sufficiently up-to-date in terms of its definition, interpretation and use. With each successive revision of the Standard
Occupational Classification, in 2000 and now for 2010, the broad structure of the classification at the major (single digit) and sub major (two digit) group levels has remained virtually unchanged. However, for SOC2010 this masks a major change that has been implemented to achieve comparability with managerial occupations at this broad level in other countries. Also, the upgrading of nursing occupations from major group 3 to 2 creates another significant discontinuity at the major group level.

This section considers various methods which could help both producers and users of statistical information to understand the impact of these discontinuities at various levels of aggregation as statistical sources gradually adopt SOC2010. These are:

- historical dual-coding of specific data sets

- continuous dual-coding of specific data sets

- 'index' coding

Examples of each of these, together with an evaluation of their costs and benefits, are considered in the following sub-sections.

Historical dual coding of specific data sets

This is the most common approach to the problems posed by the introduction of a new classification. A number of historical data sets are recoded from the old to the new classification. Analysis of the dual-coded data reveals the impact of reclassification on the size and structure of the occupationally classified data.

In the process of developing SOC2010, three data sets were recoded from SOC2000 to SOC2010. These are: the DecemberFebruary quarter of the Labour Force Survey, 1996/97; the January-March quarter of the Labour Force Survey 2007 and the 1 per cent sample of the 2001 Census of Population for England and Wales. Figure 1 and 2 showed how such information can be used graphically to portray the major effects of reclassification. The same information can also be used to generate detailed matrices (for example, cross-classifications of occupational data by the old and new classifications at various levels of aggregation of the classification and by gender) which can be used to transpose a vector of data classified by the old classification to the new classification. Such techniques are only useful if there is a fairly stable relationship between the old and the new classifications at the level of aggregation for which converted information is required. This is not usually a sustainable assumption over a long time period. 


\section{Figure $2 a$ \\ Percentage distribution of female employment in Dec 1996-Feb 1997, SOC2000 and SOC2010}

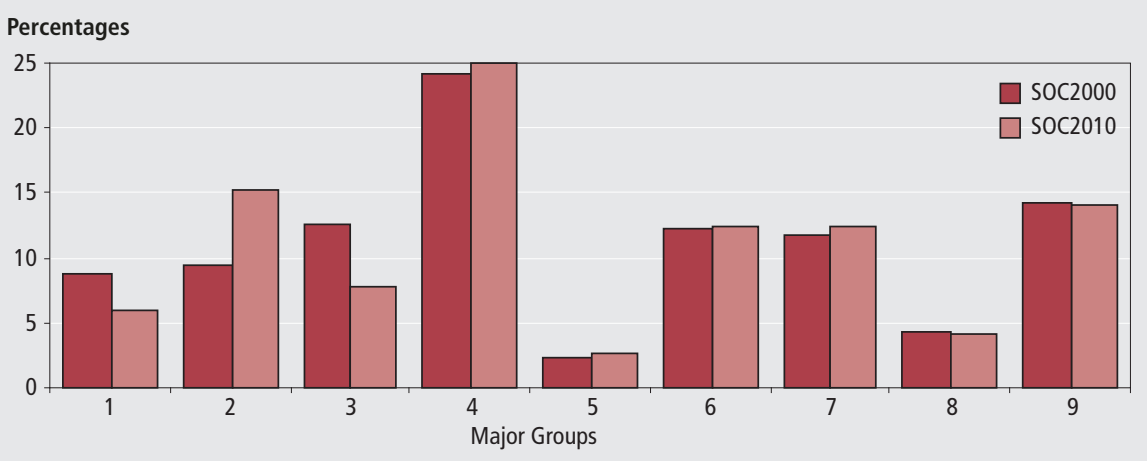

Source: Labour Force Survey (unweighted data)

\section{Figure $2 b$ \\ Percentage distribution of female employment in Jan-Mar 2007, SOC2000 and SOC2010}

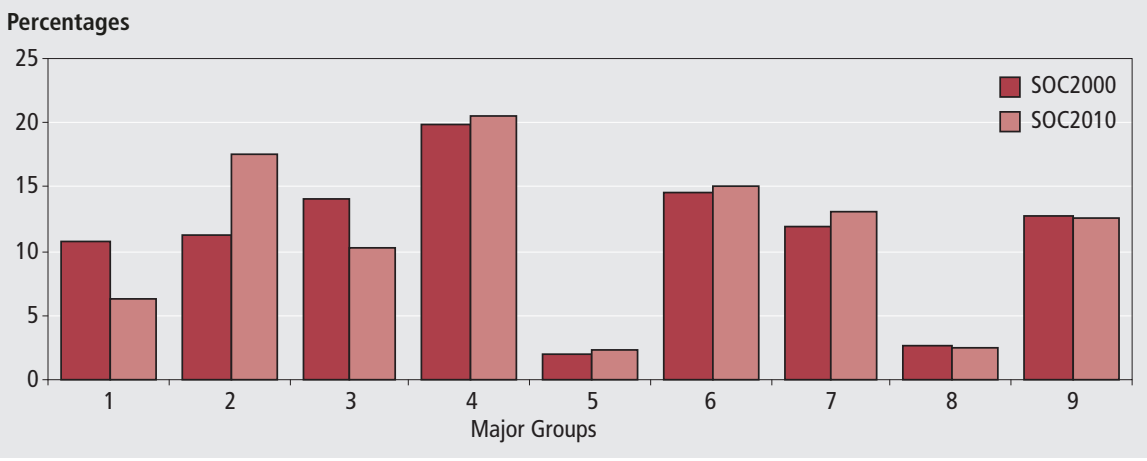

Source: Labour Force Survey (unweighted data)

Continuous dual-coding of specific data sets

Modern coding techniques employ coding software which attempts to match a job description (usually a text description of a job title) to a relevant index entry to which an occupational code has been assigned. This software can produce both 'old' and 'new' codes during the coding process. Thus, a single coding process generates information that allows the producer of occupational statistics to supply information tabulated according to either the old or the new classifications. This raises questions about the length of time for which such dual-coded statistical information should be available to users and may inhibit users from switching from the old to the new classification.

\section{Index coding}

Index coding provides a compromise between these two methods. It is continuous, in that a code is generated from the coding process that allows the statistical producer to output both the new and the old classifications. A unique and permanent index code becomes part of the output stream from the coding process and is preserved for future use. A 'look-up' table relates the index code to the current classification. The producer can decide for how long information will be made available via both the old and the new classification. It has the added advantage that, if the classification changes again in the future, a revised look-up table can be used to reprocess earlier data from the index code to the latest version of the classification.

Index coding was attempted in a partial sense with the 'component codes' used for the 1991 Census of Population. However, these codes did not reference the underlying index entry that had yielded a specific occupational code from the job title. If all job titles have a unique reference code, reclassification of existing data to a new classification becomes a fairly trivial task. This technique has the added advantage that it provides a framework for 'dynamic updating' of the index to the classification. Users can see how new index entries are placed within the classification.

Coder unfamiliarity with the index codes can be minimised by using the first four digits of the latest version of the classification as reference digits, followed by two alphanumeric characters to generate a unique index reference code ${ }^{9}$. However, with each successive revision of the classification, the initial four digits will have less relevance.

Summary of the advantages and disadvantages of various methods dealing with continuity

Table 7 outlines the advantages and disadvantages associated with each specific method.

\section{Notes}

1. OPCS (1990a, 1990b).

2. ONS (2000a, 2000b).

3. Major Group 1 is defined as 'managers' in both SOC2000 and the 1988 International Standard Classification of Occupations (ISCO 88).

4. Cyprus, Italy and Romania deviate by approximately -2.6 percentage points. Similar tabulations received by the IER from Eurostat for 2006 show the same pattern.

5. Ireland uses an occupational classification based on the UK Standard Occupational Classification. For the 2006 Census of Population the version used was based on SOC90.

6. Discussion were held with occupational experts from Germany, Netherlands, USA, Norway at the European Social Survey Quality Enhancement Workshop, Mannheim, 27 September 2008 and with experts from a wide range of countries at the Harmonisation Workshop, Council of European Social Survey Data Archives, Paris 3 April 2008.

7. ISCO88, the 1988 version of the International Standard Classification of Occupations is currently being revised and will be published shortly as ISCO08: www.ilo.org/public/english/ bureau/stat/isco/isco08/index.htm.

8. The Labour Force Survey files from which job title and related information was extracted were: October-December 2002; September-November 2003; April-June 2004; October-December 2005; January-March 2007.

9. Thus allowing over 700 job titles to share the same four digit code.

\section{CONTACT}

四elmr@ons.gov.uk

\section{REFERENCES}

Elias P, McKnight A, Davies R and Kinshott $G$ (2000) 'The revision of the Standard Occupational Classification from its 1990 version to SOC2000', Labour Market Trends, pp. 563-572. 
Table 6

\section{Correspondence between SOC2010 and SOC2000 at level of sub major groups}

\begin{tabular}{|c|c|c|c|c|}
\hline & \multirow[b]{2}{*}{ SOC2010 sub major group } & \multicolumn{3}{|c|}{ Correspondence with SOC2000 sub major group (per cent) } \\
\hline & & Same & Other* & r group) \\
\hline 11 & Corporate managers and directors & 99 & & \\
\hline 12 & Other managers and proprietors & 90 & $10(11)$ & \\
\hline 21 & Science, research, engineering and technology professionals & 67 & $21(11)$ & $5(23)$ \\
\hline 22 & Health professionals & 27 & $71(32)$ & \\
\hline 23 & Teaching and educational professionals & 98 & & \\
\hline 24 & Business, media and public service professionals & 64 & $19(11)$ & $7(34)$ \\
\hline 31 & Science, engineering and technology associate professionals & 91 & $3(21)$ & $4(81)$ \\
\hline 32 & Health and social care associate professionals & 91 & $4(24)$ & \\
\hline 33 & Protective service occupations & 93 & $5(11)$ & \\
\hline 34 & Culture, media and sports occupations & 97 & & \\
\hline 35 & Business and public service associate professionals & 68 & $24(11)$ & $5(41)$ \\
\hline 41 & Administrative occupations & 88 & $9(11)$ & \\
\hline 42 & Secretarial and related occupations & 92 & $5(41)$ & \\
\hline 51 & Skilled agricultural and related trades & 99 & & \\
\hline 52 & Skilled metal, electrical and electronic trades & 94 & & \\
\hline 53 & Skilled construction and building trades & 94 & $4(81)$ & \\
\hline 54 & Textiles, printing and other skilled trades & 85 & $10(12)$ & \\
\hline 61 & Caring personal service occupations & 97 & & \\
\hline 62 & Leisure, travel and related personal service occupations & 90 & $3(12)$ & $6(92)$ \\
\hline 71 & Sales occupations & 96 & $2(11)$ & \\
\hline 72 & Customer service occupations & 67 & $19(41)$ & $14(11)$ \\
\hline 81 & Process, plant and machine operatives & 91 & $8(91)$ & \\
\hline 82 & Transport and mobile machine drivers and operatives & 98 & & \\
\hline 91 & Elementary trades and related occupations & 96 & & \\
\hline 92 & Elementary administration and service occupations & 87 & $13(91)$ & \\
\hline
\end{tabular}

Note:

Source: Labour Force Survey, Jan-Mar 2007

* only reported if $>2 \%$.

Table 7

Advantages and disadvantages of various methods for dealing with discontinuities arising from classification change

\begin{tabular}{|c|c|c|}
\hline Method & Advantages & Disadvantages \\
\hline Historical dual-coding of specific data sets & $\begin{array}{l}\text { Relatively easy to produce } \\
\text { Gives clear indication of changes arising from } \\
\text { introduction of new classification }\end{array}$ & $\begin{array}{l}\text { If used to convert data for other time periods, or from other sources, it may give } \\
\text { rise to misleading and inaccurate estimates }\end{array}$ \\
\hline $\begin{array}{l}\text { Continuous dual-coding of specific data } \\
\text { sets }\end{array}$ & - Simple to introduce & $\begin{array}{l}\text { May be confusing for coders and statistical users } \\
\text { May discourage users from adopting the new classification }\end{array}$ \\
\hline Index coding & $\begin{array}{l}\text { Relatively simple to introduce } \\
\text { Gives structure to index and allows users to see where } \\
\text { changes are made } \\
\text { - Allows for dynamic index updating } \\
\text { - 'Future proofs' the data against further classification } \\
\text { changes }\end{array}$ & $\begin{array}{l}\text { Data need to be reprocessed at micro-data level to produce new classification } \\
\text { Index codes themselves are initially meaningless beyond four digits and become } \\
\text { progressively difficult to interpret with successive revisions to the classification }\end{array}$ \\
\hline
\end{tabular}

Source: SOC2000 and SOC2010

European Commission (2004) 'Employment in Europe. Recent Trends and prospects', Luxembourg: Office for Official Publications of the European Communities.

Office for National Statistics (2010a)

'Standard Occupational Classification 2010

Volume 1: Structure and Descriptions of Unit Groups', Basingstoke: Palgrave Macmillan.

Office for National Statistics (2010b)

'Standard Occupational Classification 2010 Volume 2: The Coding Index', Basingstoke: Palgrave Macmillan.
Office for National Statistics (2000a) 'Standard Occupational Classification 2000 Volume 1: Structure and Definition of the Unit Groups', London: The Stationery Office.

Office for National Statistics (2000b) 'Standard Occupational Classification 2000 Volume 2: Index', London: The Stationery Office.

Office of Population Censuses and Surveys (1990a) 'Standard Occupational Classification Volume 1', London: The Stationery Office.
Office of Population Censuses and Surveys (1990b) 'Standard Occupational Classification Volume 2'. London: The Stationery Office.

Thomas R and Elias P (1989). 'The development of the Standard Occupational Classification', Population Trends 55 Spring 1989. 